\title{
OPEN Genomic prediction for growth using a low-density SNP panel in dromedary camels
}

\author{
Morteza Bitaraf Sani ${ }^{1 凶}$, Javad Zare Harofte ${ }^{1}$, Mohammad Hossein Banabazi², \\ Saeid Esmaeilkhanian ${ }^{3}$, Ali Shafei Naderi ${ }^{1}$, Nader Salim ${ }^{4}$, Abbas Teimoori ${ }^{4}$, Ahmad Bitaraf ${ }^{1}$, \\ Mohammad Zadehrahmani ${ }^{5}$, Pamela Anna Burger ${ }^{6}$, Vincenzo Landi ${ }^{7}$, Mohammad Silawi ${ }^{8}$, \\ Afsaneh Taghipour Sheshdeh ${ }^{8} \&$ Mohammad Ali Faghihi ${ }^{8,9}$
}

For thousands of years, camels have produced meat, milk, and fiber in harsh desert conditions. For a sustainable development to provide protein resources from desert areas, it is necessary to pay attention to genetic improvement in camel breeding. By using genotyping-by-sequencing (GBS) method we produced over 14,500 genome wide markers to conduct a genome- wide association study (GWAS) for investigating the birth weight, daily gain, and body weight of 96 dromedaries in the Iranian central desert. A total of 99 SNPs were associated with birth weight, daily gain, and body weight ( $p$-value $<0.002$ ). Genomic breeding values (GEBVs) were estimated with the BGLR package using (i) all 14,522 SNPs and (ii) the 99 SNPs by GWAS. Twenty-eight SNPs were associated with birth weight, daily gain, and body weight ( $p$-value $<0.001$ ). Annotation of the genomic region (s) within $\pm 100 \mathrm{~kb}$ of the associated SNPs facilitated prediction of 36 candidate genes. The accuracy of GEBVs was more than 0.65 based on all 14,522 SNPs, but the regression coefficients for birth weight, daily gain, and body weight were $0.39,0.20$, and 0.23 , respectively. Because of low sample size, the GEBVs were predicted using the associated SNPs from GWAS. The accuracy of GEBVs based on the 99 associated SNPs was $0.62,0.82$, and 0.57 for birth weight, daily gain, and body weight. This report is the first GWAS using GBS on dromedary camels and identifies markers associated with growth traits that could help to plan breeding program to genetic improvement. Further researches using larger sample size and collaboration of the camel farmers and more profound understanding will permit verification of the associated SNPs identified in this project. The preliminary results of study show that genomic selection could be the appropriate way to genetic improvement of body weight in dromedary camels, which is challenging due to a long generation interval, seasonal reproduction, and lack of records and pedigrees.

For thousands of years' camels have produced meat, milk, and fiber in harsh desert conditions. There are 35 million camels globally (FAO, 2019), 95\% of which are dromedaries ${ }^{1}$. The innate characteristics of adaptability and sustainability of the productions can be in antagonism as already proven for example in the bovine species ${ }^{2}$. Thus, the development of a modern genetic improvement program for the productivity of the dromedary should be accompanied by a profound understanding of its genome and the mechanisms of inheritance of the characters of interest ${ }^{3}$. The ability to blend together the adaptability to hot climates and its innate rusticity with an efficient production capacity would make this animal an excellent alternative in marginal environments ${ }^{3}$. In local population, the lack of phenotypic records and pedigrees, small herd size and missing connectedness, and

\footnotetext{
${ }^{1}$ Animal Science Research Department, Yazd Agricultural and Natural Resources Research and Education Center, Agricultural Research, Education \& Extension Organization (AREEO), 8915813155 Yazd, Iran. ${ }^{2}$ Department of Biotechnology, Animal Science Research Institute of IRAN (ASRI), Agricultural Research, Education \& Extension Organization (AREEO), 3146618361 Karaj, Iran. ${ }^{3}$ Department of Biotechnology, Animal Science Research Institute of IRAN (ASRI), Agricultural Research, Education and Extension Organization (AREEO), 3146618361 Karaj, Iran. ${ }^{4}$ Organization of Agriculture - Jahad -Yazd, Ministry of Agriculture-Jahad, 8916713449 Yazd, Iran. ${ }^{5}$ Yazd Dar Al-Elm Higher Education Institute, Yazd, Iran. ${ }^{6}$ Research Institute of Wildlife Ecology, Vetmeduni Vienna, 1160 Vienna, Austria. ${ }^{2}$ Departement of Veterinary Medicine, Università Di Bari "Aldo Moro", Bari, Italy. ${ }^{8}$ Persian BayanGene Research and Training Center, 7134767617 Shiraz, Iran. ${ }^{9}$ Center for Therapeutic Innovation and Department of Psychiatry and Behavioral Sciences, University of Miami, Miami, FL 33136, USA. ${ }^{\square}$ email: m.bitaraf@areeo.ac.ir
} 
genetic evaluations are the main limitations ${ }^{4}$. Genomic approaches can be beneficial to reduce the impact of these problematic ${ }^{5}$.

Next-generation sequencing platforms have prepared suitable approaches for genome wide association studies and genomic selection at the whole-genome level ${ }^{6}$. By using genotyping-by-sequencing (GBS) method can be produced many genome wide markers, which is a that supports GWAS ${ }^{7,8}$. GBS has been widely used in plant and animal breeding for genome-wide association analysis, genomic diversity studies, and genomic selection ${ }^{9}$. The availability of reference genome assemblies coupled with GBS enables us to explore in greater detail of dromedary populations and to identify genetic associations with different phenotypic traits ${ }^{10}$. Genome-wide association studies (GWAS) are used to screen the whole genome for target genes that correlate with phenotypic traits, using SNPs and an important method for identifying candidate genes for important economic traits in livestock ${ }^{11}$. GWAS have a greater capability than QTL mapping to detect causal SNPs in a smaller genetic range ${ }^{12}$. In recent years, many genes and molecular markers, regulate important traits, were identified using GWAS in livestock animals like pigs, cattle, sheep, and chickens ${ }^{13,14}$. Despite its unique potential and increased contribution to food security, comparatively less attention has been paid to camels compared to other livestock species ${ }^{3}$.

Body growth is an economical important trait in dromedaries. The birth and weaning weight, gain per day, and body weights at different ages are used to reflect the growth and development. Growth in weight is a heritable trait and an important index of selection ${ }^{17}$. Although meat production and its functionality are strategic topics in camel breeding, which is reflected by the increasing interest of stakeholders and consumers in camel products, few studies have been produced in this field.

In Iran, there are about 140,000 dromedary camels (FAO, 2019) that are divided into four basic types: meat type, milk type, dual purpose and riding camels ${ }^{18}$. Camels in the central desert of Iran usually belong to the meat type with a large and heavy muscular head, short neck, large hump, wide posterior parts and firm body ${ }^{19}$. The camels are kept by the villagers located around the desert. The camels are gathered usually in spring. While the young camels are sold the remaining herds are returned to the desert. During the summer, the camels need more water, so they return to the villages every day. The size of herds may vary from 4-5 up to 100-150 animals.

The present study has been designed to gain first knowledge on body weight traits at different age in the Iranian dromedary population, and to understand their underlying genomic characteristics. We collected a large number of phenotypic measurements in 96 dromedaries in the Central Desert of Iran as well as genotypes by GBS approach. We applied GWAS to identify candidate genes for growth related traits and estimated GEBVs for selected SNPs. This study is a first step towards systematic genomic breeding and selection in dromedaries for the benefit of local communities depending on camels as resource for income and food.

\section{Materials and methods}

Ethics statement. All of the animal procedures were performed in strict accordance with the guidelines and regulations proposed by the Animal Science Research Institute of Iran. All the animal experiments were approved by ethics committee of the Animal Science Research Institute of Iran under the number ASRI-34-641357-005-970,180. Blood samples were collected during qualified veterinary treatment within the framework of governmental programs aimed at the animal identification, monitoring of health, and parentage confirmation of the dromedary populations included in our study. No other kind of tissue was used in this study.

Animals and sample collection. Yazd province with the area of $129,285 \mathrm{~km}^{2}(49,917 \mathrm{sq} \mathrm{mi})$ is situated at an oasis where the Dasht-e Kavir desert and the Dasht-e Lut desert meet and located in $31^{\circ} 53^{\prime} 41.28^{\prime \prime} \mathrm{N}, 54^{\circ}$ $21^{\prime} 25.2^{\prime \prime} \mathrm{E}(31.8948,54.357)$. Data on 51 herds of dromedaries were collected in 2018. The herd size mean was 89.90 , range from 11 to 400 heads among 4279 camels, $16 \%$ were younger than one year, and named Hashi, while $12 \%$ were older than ten years. The proportion of females (Arvaneh), males (Lok), male calves (Hashi), and female calves (Hashi) were $76 \%, 9 \%, 6 \%$, and $9 \%$, respectively. Among pregnant camels, $49 \%$ were older than ten years. The ratio of pregnant camels to all female camels was $46 \%$. A total of 964 calving was registered between January to May 2018, distributed over 22\% in January, 28\% in February, 27\% in March, 15\% in April, and 8\% in May. Generation intervals in females and males were estimated at 7.84 and 5.91 years, respectively. Among 256 male calves, we recorded 96 samples from 5 regions including: Bafgh $(n=41)$ Bahabad $(n=8)$, Khatam $(\mathrm{n}=17)$, Mehriz $(\mathrm{n}=8)$, and Ardakan $(\mathrm{n}=22)$. Characteristics of the sampled herds and the rangeland plants are presented in Table 1.

Phenotypic measurements. Data were recorded at the morning before grazing on the pasture. Camels were kept in closed area at night, which is called Garch. The animal identification was inferred via three-digit ear tags. Due to large distance in remote regions and transport difficulties, we constructed a portable weighting scale, consisting of 13 pieces of iron, a digital scale for $2000 \mathrm{~kg}$, and one chain crane (Fig. 1). The meta data collected for any calf included: ID number, characteristics of owner, geographical region, recording date, birth date, parental names, and body weight. We recording intervals were approximately three months, with the first record starting in the calving season, the second during the summer, and the third at weaning season at the beginning of autumn. We collected 252 body weight records from 96 calves in different times during 2018. The 18 calves belong to National Research and Development Station on Dromedary Camel (Bafgh), measured in 8 -times, the others were recorded 2 or 3-times including: Bafgh $(n=164)$, Bahabad $(n=8)$, Khatam $(n=26)$, Mehriz $(n=9)$, Ardakan (45).

For adjusting the body weight trait, the growth trend was estimated using linear regression model (Eq. 1). Analysis of covariance (ANCOVA) of body weight was did among five sampling regions using SPSS v.22 software $^{20}$. The mean of differences was compared using LSD test. Daily weight gain was calculated by two or three-times records. 


\begin{tabular}{|c|c|c|c|c|}
\hline Region & Herd size & Sampling site & n samples & The rangeland plants \\
\hline Bahabad & 400 & $31^{\circ} 52^{\prime} 29.6^{\prime \prime} \mathrm{N} 56^{\circ} 01^{\prime} 14.7^{\prime \prime} \mathrm{E}$ & 8 & $\begin{array}{l}\text { Seidlitzia Rosmarinus, Artemisia spp, Salsola yazdiana, Tamarix tetragyna, Alhagi camelorum, Calligonum como- } \\
\text { sum, Zygophyllum spp }\end{array}$ \\
\hline Khatam & 112 & $30^{\circ} 28^{\prime} 42.4^{\prime \prime} \mathrm{N} 54^{\circ} 12^{\prime} 36.7^{\prime \prime} \mathrm{E}$ & 17 & $\begin{array}{l}\text { Seidlitzia rosmarinus-Haloxylon ammodendron, Artemisia sieberi-Seidlitzia Rosmarinus, Tamarix tetragyna, } \\
\text { Alhagi camelorum, Salsola yazdiana-Calligonum polygonoides, Zygophyllum atriplicoides }\end{array}$ \\
\hline Ardakan & 450 & $32^{\circ} 31^{\prime} 40.8^{\prime \prime} \mathrm{N} 55^{\circ} 14^{\prime} 32.9^{\prime \prime} \mathrm{E}$ & 22 & Salsola yazdiana, Haloxylon ammodendron, Artemisia sieberi, Zygophyllum spp \\
\hline Mehriz & 320 & $31^{\circ} 35^{\prime} 14.4^{\prime \prime} \mathrm{N} 54^{\circ} 25^{\prime} 44.4^{\prime \prime} \mathrm{E}$ & 8 & Haloxylon ammodendron-Zygophyllum atriplicoides, Artemisia sieberi-Salsola arbuscula, \\
\hline \multicolumn{4}{|l|}{ Bafgh $^{*}$} & \multirow{3}{*}{ Zygophyllum spp, Seidlitzia Rosmarinus, Artemisia sieberi, Zygophyllum spp, Salsola yazdiana } \\
\hline Herdl & 117 & 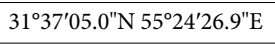 & 23 & \\
\hline Herd2 & 100 & & 18 & \\
\hline
\end{tabular}

Table 1. Characteristics of sampling herds and the rangeland plants. ${ }^{\star}$ Two herds in Bafgh were recorded (1: local herd and 2: National Research and Development Station on Dromedary Camel herd).

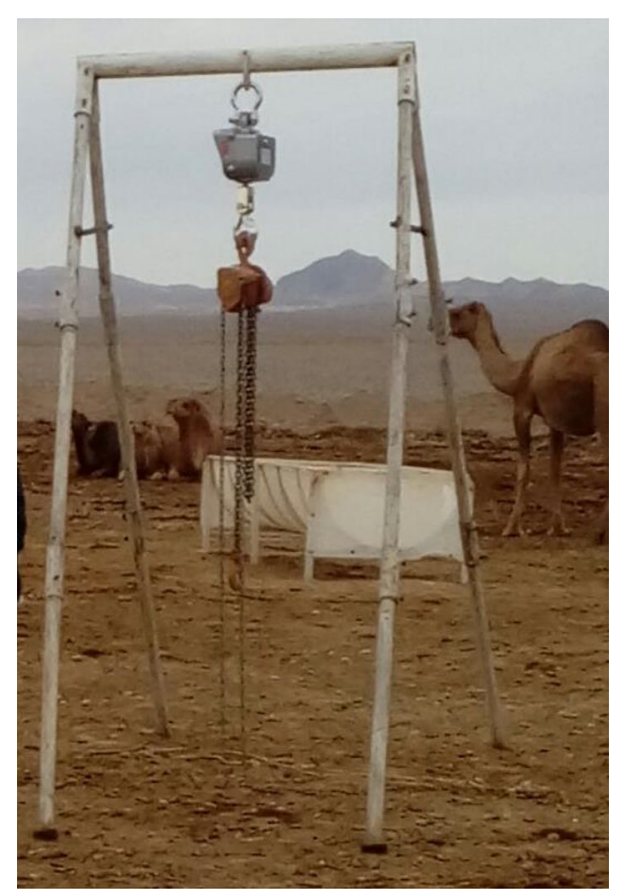

Figure 1. The portable weighting scale (Company: Fuzhou Kejie Intelligent Technology Co.,Ltd. model: OCS-XZ-2, 2000 Weigh Capacity (Kg), Accuracy Class III, + /- 1 division (least count). This were made from 13 pieces of iron, hanging digital scale $2000 \mathrm{~kg}$, and one chain crane.

$$
y_{i j}=\mu+\tau_{i}+\beta\left(x_{i j}-\bar{x}\right)+\epsilon_{i j}
$$

$y_{i j}$ : body weight; $\mu$ : Effect of mean; $\tau_{i}$ : sampling regions includes: (Bafgh, Bahabad, Khatam, Ardakan, and Mehriz); $\beta$ : The regression coefficient; $x_{i j}$ : Age of recording; $\bar{x}$ : average of recording Ages.

DNA extraction, SNP discovery and genotyping. Blood samples were collected from the jugular vein in EDTA tubes during routine veterinary treatment on the pasture. The genomic DNA was extracted using the modified salting-out method ${ }^{21}$ and, after elution, was quantified using spectrophotometry and checked for quality on a $1 \%$ agarose gel. Finally, DNA samples were adjusted to a concentration of $50 \mathrm{ng} / \mu \mathrm{l}$ for subsequent steps.

The samples were genotyped-by-sequencing using two restriction enzymes combination, EcoR1 and HinF1 (New England Biolabs, Ipswich, MA, USA), and paired-end (150 bp) sequencing (10 X) on the Illumina HiSeq 2000 platform by Persian Bayangene Research and Training Center (Shiraz, Iran).

The sequence reads were mapped to the dromedary reference genome assembly on chromosome level (GCA_000803125.3[1];) by using the BWA-MEM algorithm of Burrows-Wheeler Aligner (BWA) ${ }^{22}$;. PCR duplicates were detected by utilizing Picard tools and disregarded in downstream analyses both by GATK ${ }^{23}$ and SAMtools $^{24}$. SNPs were called across the GBS data using GATK. 
Population structure andd genetic diversity. A quality control (QC) steps, and genome-wide diversity (observed and expected heterozygosity), as well as admixture analyses were performed using TASSEL V5.023. Variants with a minor allele frequency (MAF) below 0.05 and call rate below 0.95 were removed. Of the 41,897 SNPs, 256 markers were monomorphic, and 27,375 markers were deleted because of MAF $<0.05$. The final data set consisted of 14,522 SNPs and 96 individuals. To investigate population structure, we used vcfR package ${ }^{25}$ in $\mathrm{R}$ for data manipulation and quality control as for producing input file objects for the other analysis, after that using ape and poppr package ${ }^{26}$ we carried out K-means clustering and discriminant analysis of principal components (DAPC), while all graphics were produced by means of RColorBrewer ${ }^{27}$.

Linkage disequilibrium analysis (LD) and SNP-based haplotype blocks estimating. TASSEL $5.0^{28}$ was used to calculate the linkage disequilibrium (LD) $\left(\mathrm{r}^{2}\right)$ for all pairwise loci. Haplotype blocks (HAP) were constructed in Haploview ${ }^{29}$.

Genome-wide association studies and candidate genes prediction. The association between the SNPs and the traits were tested using mixed linear models with PCA and kinship matrix in TASSEL software ${ }^{28}$. The regions of this study and age at weighting date were used as a fixed and covariate effect, respectively.

The statistical analysis model, the MLM-PCA $+\mathrm{K}$ analysis, was expressed as:

$$
y=\alpha X+\beta P+U Z+e
$$

where y was phenotype value; $\alpha$ was the vector of SNP effects; $\beta$ was vector of population structure effects based on PCA; $\mathrm{u}$ was vector of kinship background effects; $\mathrm{e}$ was vector of residual effects; $\mathrm{X}, \mathrm{P}, \mathrm{Z}$ were incidence matrix relating the individuals to fixed marker effects $\alpha$, fixed principal component (PC) effects $\beta$, random group effects $\mathrm{u}$, respectively. The suggestive significant Bonferroni P-value thresholds were set $(-\log \mathrm{p}$ value $>3.9)$ using the GEC software tool ${ }^{30}$. The associated SNPs (-Log p value $>3$ ) was traced in NCBI and the candidate genes were detected by blasting to the dromedary camel's genome (GCA_000803125.3). We considered genes associated with the respective SNPs, if they were located either within the exon/ intron of a gene or within a flanking region of $100 \mathrm{~kb}$ up- and downstream.

Bayesian genomic prediction. The estimation of Genomic Breeding values (GEBVs) was performed with the BGLR package including BRR, Bayes A, B, and C approach (nIter $=100 \mathrm{k}$, Burn In $=5 \mathrm{k})^{31}$. two sets of SNPs were used to predict GEBV: (1) all 14,522 SNPs and (2) the 99 associated SNPs (-Log p value $\geq 2.5$ from GWAS). The prediction accuracy was estimated using the average Pearson's correlation $(\mathrm{r})$ and regression $(\mathrm{b})$ coefficient between the GEBVs and observed values ${ }^{32-34}$. The replicated training-testing approach (10 replications) was used for evaluation of the models. We also used 3:1 size ratio of training set and validation set randomly selected from the 96 camels, which is a three-folds cross-validation, and repeated 100 times for evaluation of models by the 99 associated $\mathrm{SNPs}^{35,36}$.

\section{Result}

Phenotypic statistics of body weight traits. The distribution of 252 body weight records is visualized in Fig. 2. The growth trend of data suggested linear relationship between age and body weight $\left(\mathrm{R}_{\mathrm{adj}}{ }^{2}=0.63\right)$. Analysis of covariance for body weight records showed significant $(\mathrm{p}<0.05)$ differences among camels from five sampled regions (Table 2). The body weight of camels in Ardakan was higher than the others (except Mehriz, because camels in addition to grazing on the pasture were fed by hand. The camels of Bafgh and Bahabad didn't have significant differences. It is necessary to adjust the sampling region effect in GWAS and genomic selection.

The adjusted birth weight, daily weight gains and body weight of the 96 camels from five regions of the Iranian central desert are shown in Table 2. The descriptive statistics including the mean, standard error (SE), coefficient of variation (CV) are presented in Table 3 . The Pearson correction between daily gain with body weight $(r=0.63)$ was more than birth weight $(r=0.21)$. Also, the birth and body weight were correlated $(r=0.36)$ (Fig. 3).

\section{Summary of genotyping data}

A total of 14,522 SNPs resulted after filtering and were used for final analysis. The largest number of SNPs was identified on chromosome $9(n=1829)$ followed by chromosome $19(n=1655)$, and the smallest number of SNPs was found on chromosomes $22(\mathrm{n}=20)$ and chromosomes $23(\mathrm{n}=16)$ (Fig. 4). The average MAF of all SNPs was 0.19 , after QC (MAF>0.05) (Fig. 5). Average observed heterozygosity was $0.25 \pm 0.03$.

Genome wide association study. The MLM-PCA $+\mathrm{K}$ statistical model considering the covariates composed of population structure and kinship matrix was used for GWAS to prevent false positivity. In GWAS, the $\mathrm{p}$ value should be less than Bonferroni correction by using $\alpha / \mathrm{Me}$, where $\alpha=0.05$ and $\mathrm{Me}=$ effective number of SNPs. After applying a Bonferroni correction $\left(1.2 \times 10^{-4}\right)$, no SNPs correlated with the growth traits (Fig. 6). However, this was expected given the limited number of samples used in our study $(\mathrm{n}=96)$. A number of 28 SNPs were found to be associated with birth weight, daily gain, and body weight of dromedaries ( $\mathrm{p}$ value $<0.001$ ) (Table 4). For birth weight, 12 correlated SNPs ( $\mathrm{p}$ value $<0.001$ ) were detected on the chromosomes $7,8,9$, 11,19 , and 34 were annotated to 9 genes (Table 4 ). For daily gain, 7 correlated SNPs ( $p$ value $<0.001$ ) on the chromosomes 10,16,12, 19, and 14, were annotated to 11 genes (Table 4). For body weight, 9 correlated SNPs ( $\mathrm{p}$ value $<0.001$ ) on the chromosomes $11,8,19, \mathrm{X}, 14$, and 18 were annotated to 16 genes (Table 4). The most significant associated SNP with birth weight, daily gain, body weight, was located on chromosome 8,10 , and 11 , respectively (- $\log p$ value $=3.81,3.41$, and 3.76 , respectively). Out of the 36 genes potentially associated with 

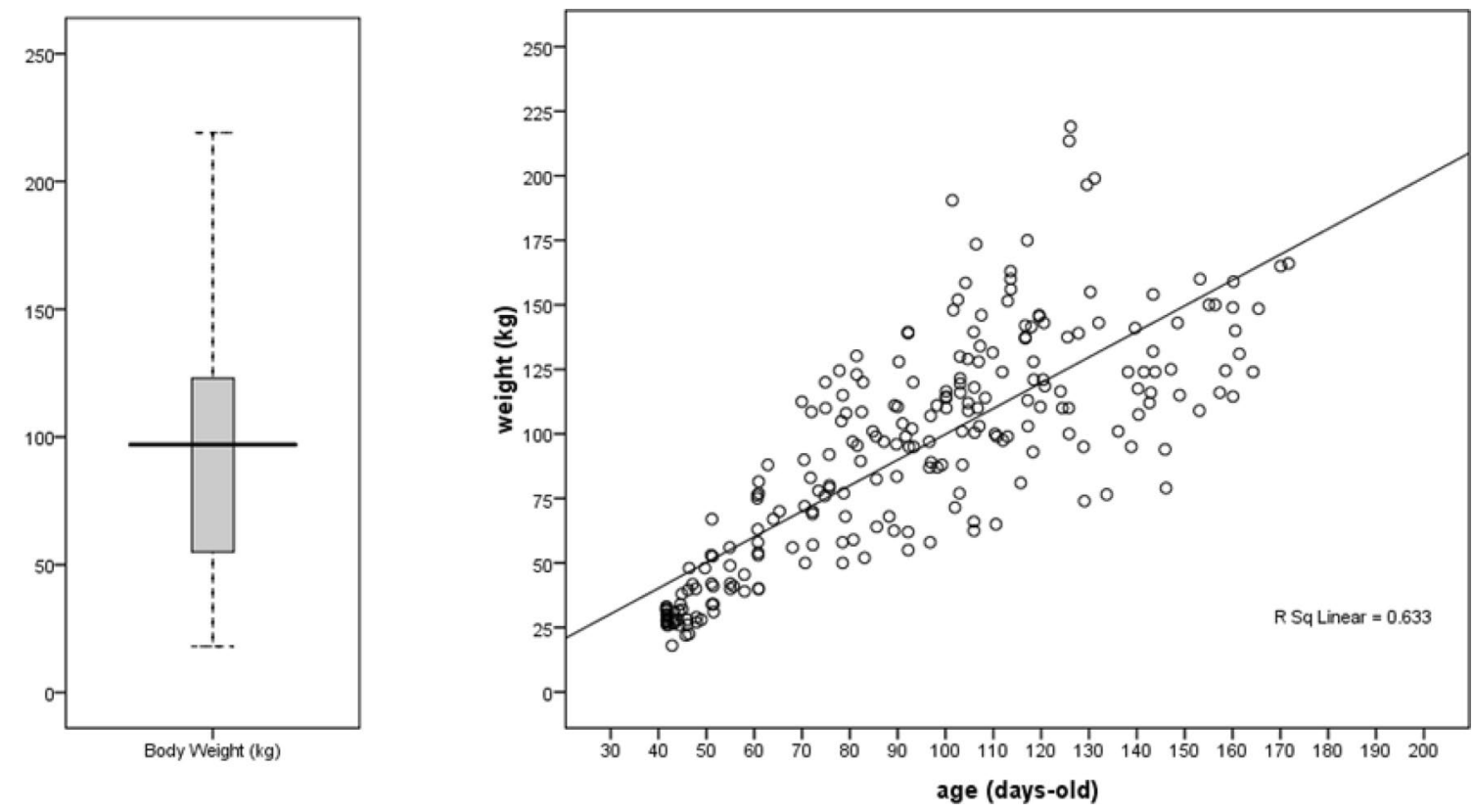

Figure 2. Box plot of 255 body weight records (left plot) and growth trend (right plot) of 96 dromedary camels in five regions of the central desert of Iran.

\begin{tabular}{|l|l|l|l|l|l|}
\hline Region & Mean $^{*}$ & SE & Confidence interval (95\%) & N records & $\mathbf{R}_{\text {adj }}{ }^{2}$ \\
\hline Bafgh & 82.90 & 1.68 & $79.58-86.22$ & 156 & \\
\cline { 1 - 3 } & 82.57 & 8.12 & $66.55-98.58$ & 7 & \multirow{2}{*}{0.77} \\
\cline { 1 - 4 } Khatam & 94.07 & 4.12 & $85.94-102.20$ & 26 & \\
\hline Ardakan & 125.17 & 3.30 & $118.65-131.69$ & 40 & \\
\hline Mehriz & 115.96 & 7.42 & $101.33-130.59$ & 8 & \\
\hline
\end{tabular}

Table 2. ANCOVA of body weight $(\mathrm{kg})$ among five regions of the central desert of Iran. ${ }^{\star}$ Age of recording included as covariate and body weight are evaluated at the Age $=155.98$ days-old.

\begin{tabular}{|l|c|l|l|}
\hline Trait & Mean & SE & CV \\
\hline Birth Weight (Kg) & 28.95 & 0.93 & $31 \%$ \\
\hline Daily gain $(\mathrm{gr})$ & 511.38 & 12.25 & $23.6 \%$ \\
\hline Body Weight $(\mathrm{kg})$ (age as covariate): From the birth date to 272 days age & 90.08 & 44 & $48 \%$ \\
\hline
\end{tabular}

Table 3. The descriptive statistics of body weight traits of dromedary camels.

peak SNPs [the genes listed in Table 4], two genes harboured the SNPs in their exon/ intron regions. Another 11 genes were detected in flanking regions of less than $30 \mathrm{~kb}$ up- and downstream of the respective SNP. Four genes were identified in 30-50 kb regions and 12 genes lay 50-100 kb up- and downstream of the potentially associated SNP.

A total of 99 SNPs were associated with the three traits (birth weight, daily gain, and body weight) at $\mathrm{p}$ value $<0.002$ (Table 5). Twelve haplotype blocks and 80 tag SNPs were predicted among the 99 associated SNPs with LD ( $\mathrm{D}>0.8)$ (Fig. 7). Majority haplotype blocks contained two SNPs and only two blocks contain 4, and 6 markers. The haplotype-traits association analysis showed the haplotype $2,3,4,5$, 9, and 12 associated with birth weight (Table 6), while four haplotypes of them associated with daily weight gain. The haplotype 8 containing six SNPs didn't associate with body weight, while The haplotype 4 was the most important haplotype associated with body weight (Table 6).

Genomic Selection Based on BGLR. Based on BRR model in BGLR, the GEBVs of each trait (birth weight, daily gain, and body weight) was estimated using all 14,522 SNPs. The GEBVs also were predicted using the 99 associated SNPs based on BRR, Bayes A, B, and C models. The averaged correlation ( $r$ ) and regression (b) coefficient between the observed and the GEBVs predicted from two SNPs sets: (1) all 14,522 SNPs and (2) the 


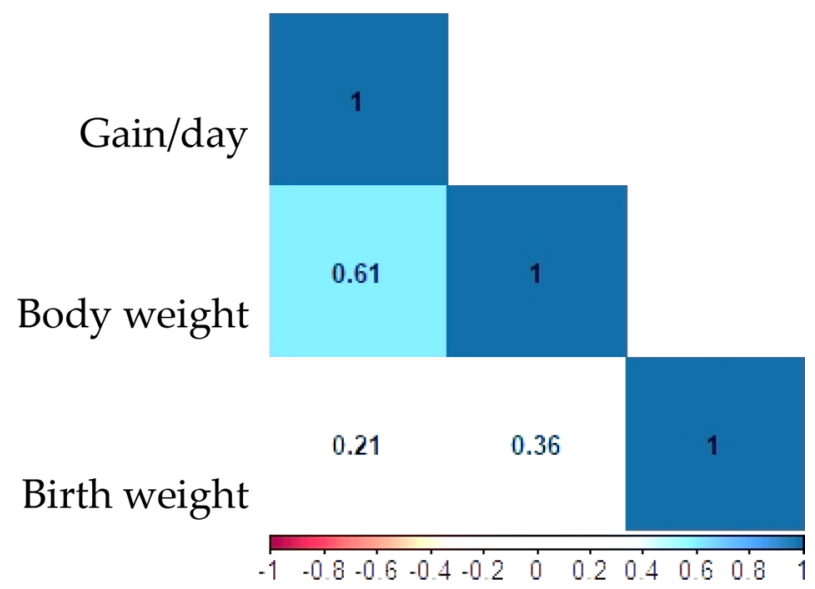

Figure 3. Correlation coefficients among birth weight, daily gain, and body weight in dromedary camels.

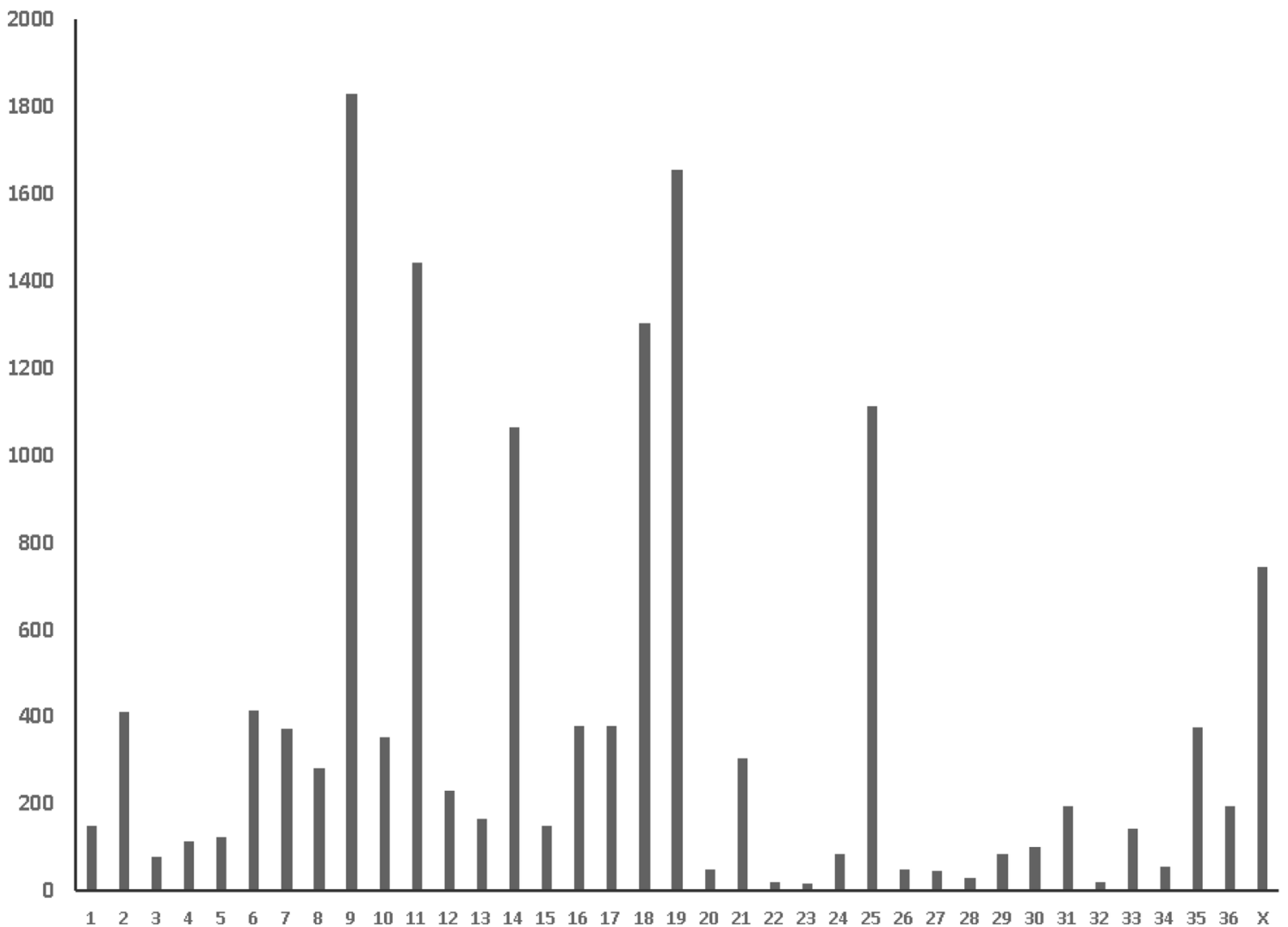

Figure 4. Number of SNPs/Chromosome.

99 associated SNPs using BGLR package (BRR model). The accuracy of GEBVs were more than 0.65 base on all 14,522 SNPs, but the regression coefficients for birth weight, daily gain, and body weight were $0.39,0.20$, and 0.23 , respectively (Table 7). the GEBVs was less biased based on the 99 associated SNPs. The accuracy of using the 99 associated SNPs also evaluated by cross- validation (3 folds and 100 replications) (Table 8). The accuracy of the BRR model was more than Bayes A, B, and C $(r>0.65)$ based on the 99 associated SNPs. the accuracy of GEBVs of body weight was less than birth weight and daily gain based on the 99 associated SNPs (Fig. 8).

\section{Discussion}

In this project, we performed a GWAS for growth traits in dromedary camels using the genotypes of 96 calves of the central desert of Iran. this is the first GWAS for birth weight, daily gain, and body weight of camels using GBS. The final goal of genetic mapping is to identify associated markers with phenotype ${ }^{37,38}$. A number of 14,522 SNPs, generated using GBS, prepared the GWAS in dromedary camels. We identified 36 candidate genes associated 


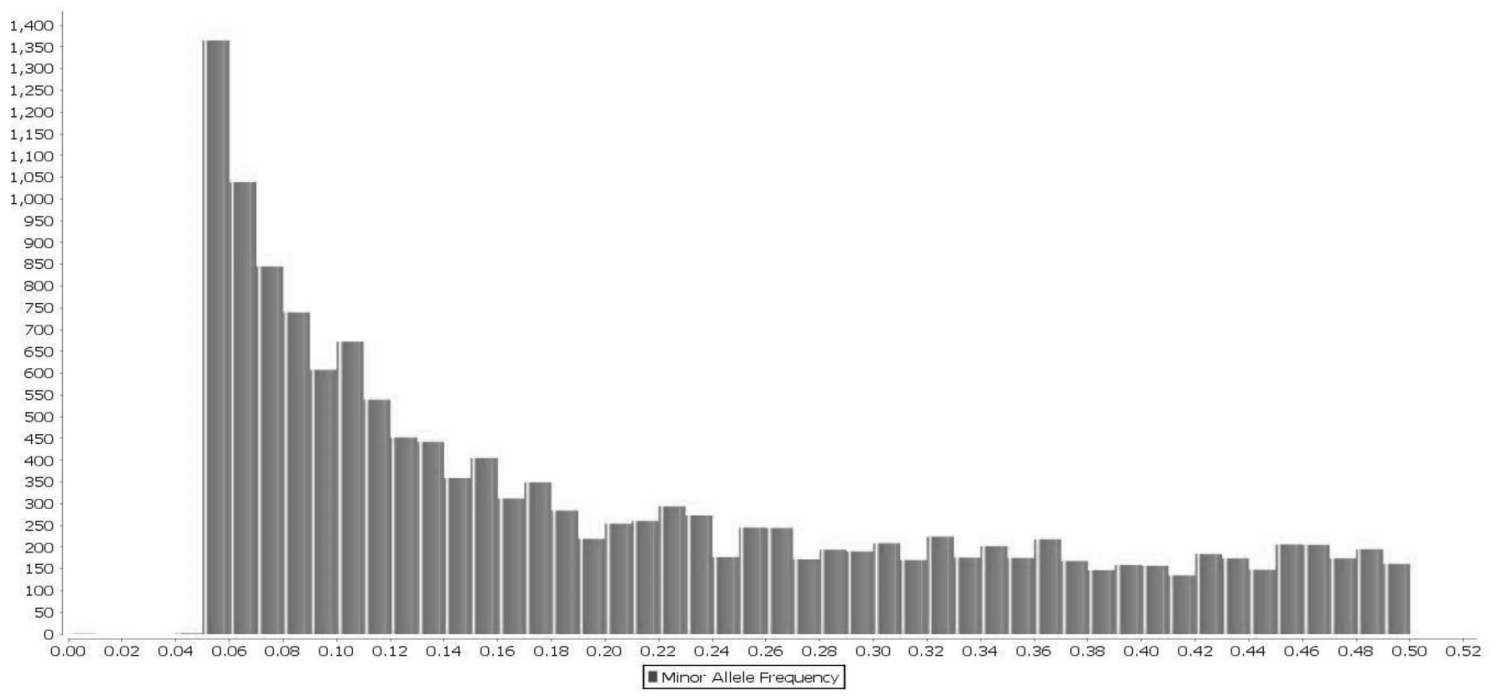

Figure 5. The Minor Allele Frequency distribution of 14,522 SNPs.

with camel's growth using Annotation of the genomic region (s) within $\pm 100 \mathrm{~kb}$ of the associated 28 SNPs. The candidate genes for birth weight of camels are ACTR3B, RPL32, XRCC2, SERAC1, TBX15, RNF114, IFNL1, SPATA2, SNAI1. For daily gain trait, EFCAB5, NSRP1, Slc6a4, ITGA7, OR6C2, RIPOR3, PTPN1, PARD6B, BCAS4, MOCS3, TRAPPC9 as candidate genes were identified. EMX2, FAM184A, MCM9, ASF1, CSE1L, ARFGEF2, TSR2, WNK3, LPAR4, RTL3, PEG10, PBDC1, TRAPPC13, UNKNOWN, DEXI, TSPYL4, CIITA were for camel body weight. The QTL regions and the genes: ADAMTSL3, CAPN2, CAPN2, FABP6, ZEB2 were detected using GWAS in Colombian Brahman cattle that influencing growth and weight traits ${ }^{39}$. Lu et al. ${ }^{11}$ (2020) reported SLCO2A1, LY6K, RALYL, AADACL3, C17H4orf45, BICC1, SHROOM2 as candidate genes for birth weight in Chinese FineWool Sheep ${ }^{11}$. The candidate genes for Dry Matter Intake, Average Daily Gain, and Metabolic Body Weight based on the imputed 7.8 M WGS in chattels were reported: SNORA70, B3GALT1, DDR2, GPR37, SYT1, LYZL1, RGS2, F13A1, SNORA31, LCORL, DPH6, PARD3, MOS, CRB1, CUL1, CCND2, ARRDC3, PLAG1, STC2, CARD11, TMEM72, SCGB1A1, ERICH6, ARRDC3, GALNT14, PLAG1, ERGIC1, AP3S2, A1CF ${ }^{40}$. An, B. et al. $(2020)^{41}$ identified the candidate genes for growth traits in Simmental beef cattle, including SOX2, SNRPD1, RASGEF1B, EFNA5, PTBP1, SNX9, SV2C, PKDCC, SYNDIG1, AKR1E2, PRIM2, SLC37A1, LAP3, PCDH7, MANEA, LHCGR, P2RY1, MPZL1, LINGO2, CMIP, and WSCD1. LOC101903200, PARP4, GPA33, NADK, PREX2, FRMD4B were identified as candidate gene for carcass weight in commercial Hanwoo cattle ${ }^{42}$.

Performance of genomic selection was determined by the prediction accuracy ${ }^{43-45}$. Until now, Genomic prediction has been conducted in many animal species. The accuracy of GEBVs for economic traits in beef cattle was predicted range 0.38 to $0.40^{46,47}$. Also, ranged from 0.18 to 0.33 for growth traits in New Zealand sheep breeds $^{48}$ It was reported range from 0.40 to 0.50 for important traits in pig ${ }^{49}$.

The statistical model, marker density, LD, and sample size influenced on selection accuracy ${ }^{43}$. The accuracy of GEBVs for growth traits was reported 0.391 (GBLUP) and 0.379 (Bayes Lasso) in Yak ${ }^{50}$. Because of low samples size in this research, it was suggested to predict unbiased GEBVs using the associated SNPs from GWAS. The accuracy of GEBV s of birth weight, daily gain, and body weight based on the 99 associated SNPs was 0.62, 0.82, and 0.57 , respectively. Using the most significant associated SNPs, the reduced SNP panels were developed for many traits ${ }^{51}$. It was resulted by the Bayes models, that some fraction of the SNPs has zero effect on the trait ${ }^{51}$. The beef industry has been focused on collections of informative SNPs for subsets of traits that have the most economic effect and market opportunity ${ }^{51}$. The 600 SNPs (20 markers / chromosome) in Bovine relatively had the same predictive ability rather than $50 \mathrm{~K} \mathrm{SNP}^{52}$, and $90 \%$ of $50 \mathrm{k} \mathrm{SNPs} \mathrm{had} \mathrm{zero} \mathrm{effect}{ }^{52}$. Garrick et al. 2011 reported that using only 384 SNPs by low costing can be achieved predictive ability for interest traits, so that the accuracies were range from 0.30 to 0.60 for growth, meat quality, and carcass weight ${ }^{53}$. The accuracies were predicted $0.28,0.29,0.39$, and 0.43 using 50,100,150 or 200 SNPs for marbling in Angus ${ }^{52}$. the haplotype-traits association analysis may also provide additional power ${ }^{54}$.

Phenotyping especially pedigree data is now the principal limitation in camel breeding. Genomic predictions do not reliant on pedigree data ${ }^{55}$, therefore it can be suggested in camel breeding because of changing into intensive farming. Establishing of training populations across countries provides an opportunity to increase training data size and genomic data in dromedaries. 

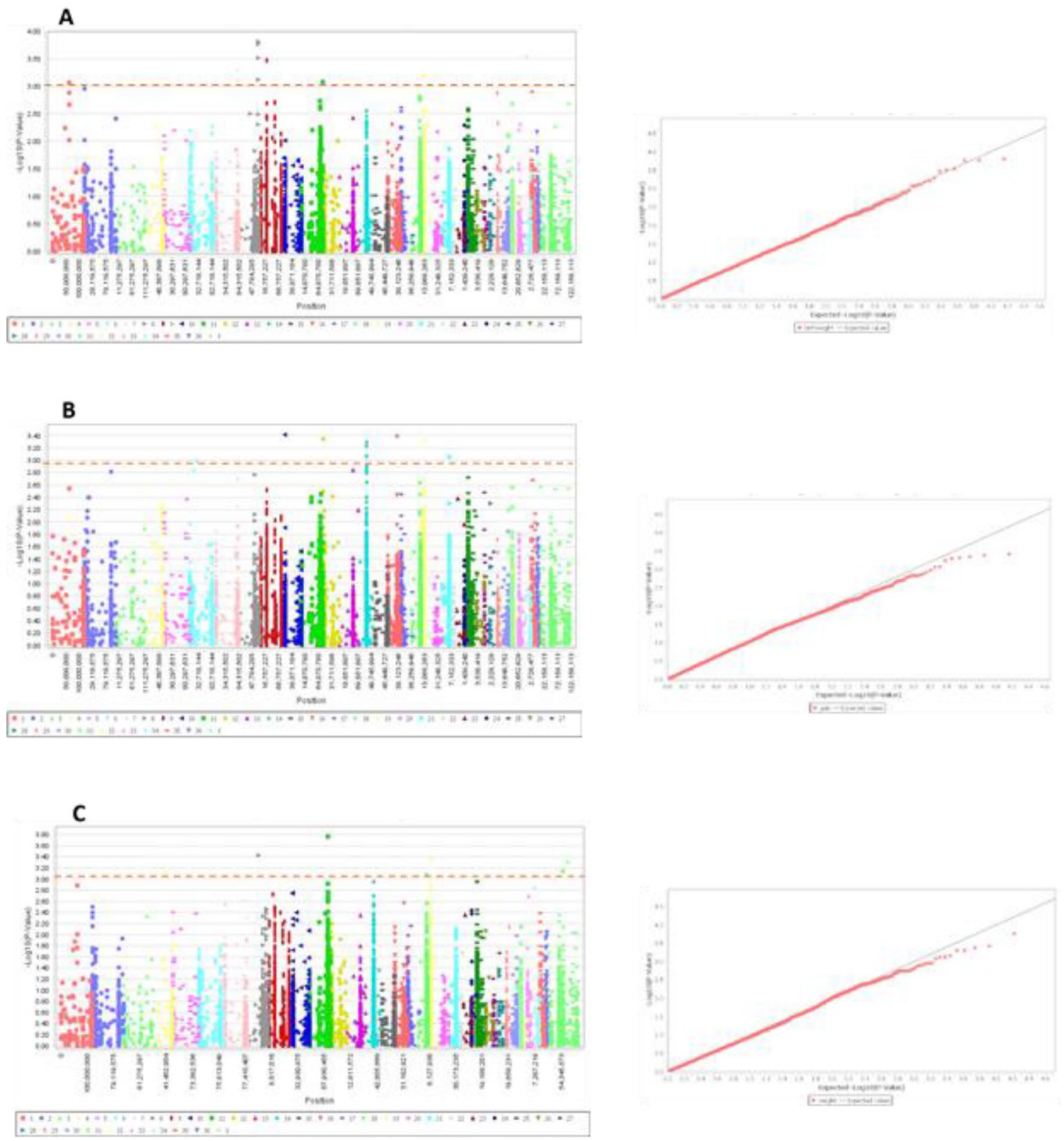

Figure 6. Manhattan plots and q-q plots of birth weight, daily gain, and body weight traits for Dromedary Camels. (A) birth weight; (B) daily gain; (C) body weight. The dotted horizontal line represents the set significant threshold $\left(-\log _{10} \mathrm{p}\right.$ value $\left.=3\right)$. Red dots in the $\mathrm{q}-\mathrm{q}$ plots represent the $-\log \mathrm{p}$-value of the entire study and the grey line represents the expected values under the null hypothesis of no association.

\section{Conclusion}

Body weight is a critical economic trait for camels and it is necessary to plan the breeding program. Detection of the genomic regions associated with growth is important for MAS (marker assisted selection) or GS (genomic selection). This is the first genome-wide association study using GBS on dromedary camels, and identifies markers associated with growth traits. This could help to plan breeding programs for genetic improvement in dromedary camels. Further studies using a larger sample size and collaboration of stakeholders will allow confirmation of the associated SNPs and candidate genes identified in this project. Because of long generation interval, no artificial insemination, and seasonal reproduction, genomic selection based on the 99 SNPs associated with growth trait could be a first step into the direction of genetic improvement for body weight in Iranian dromedaries. 


\begin{tabular}{|c|c|c|c|c|c|}
\hline Trait & Chromosome & pos & MAF & $-\log _{10}(p$-Value $)$ & Candidate gene \\
\hline \multirow{12}{*}{ Birth weight } & 7 & $82,483,685$ & 0.09 & 3.29 & \multirow{2}{*}{$A C T R 3 B, R P L 32, X R C C 2$} \\
\hline & 7 & $82,483,675$ & 0.08 & 3.10 & \\
\hline & 8 & $72,594,633$ & 0.11 & 3.81 & \multirow{5}{*}{ SERAC1 } \\
\hline & 8 & $72,594,548$ & 0.09 & 3.77 & \\
\hline & 8 & $72,594,549$ & 0.09 & 3.77 & \\
\hline & 8 & $72,594,593$ & 0.13 & 3.51 & \\
\hline & 8 & $72,594,639$ & 0.08 & 3.12 & \\
\hline & 9 & $22,550,930$ & 0.15 & 3.47 & TBX15 \\
\hline & 11 & $81,210,420$ & 0.06 & 3.07 & mRNA-hypothetical protein and KAB1271495.1 \\
\hline & 19 & $10,237,661$ & 0.05 & 3.21 & \multirow{2}{*}{ RNF114, IFNL1, SPATA2, SNAI1 } \\
\hline & 19 & $10,237,641$ & 0.05 & 3.18 & \\
\hline & 34 & $6,774,561$ & 0.06 & 3.54 & UNKHOWN \\
\hline \multirow{7}{*}{ Gain/day } & 10 & $13,892,353$ & 0.06 & 3.41 & UNKHOWN \\
\hline & 16 & $34,483,240$ & 0.39 & 3.38 & EFCAB5, NSRP1, Slc6a4 \\
\hline & 12 & 5711 & 0.02 & 3.34 & ITGA7, OR6C2 \\
\hline & 19 & $9,631,630$ & 0.17 & 3.32 & RIPOR3, PTPN1, PARD6B, BCAS4, MOCS3 \\
\hline & 14 & $31,371,259$ & 0.11 & 3.29 & \multirow{3}{*}{ TRAPPC9 } \\
\hline & 14 & $30,865,065$ & 0.23 & 3.23 & \\
\hline & 14 & $30,854,110$ & 0.37 & 3.07 & \\
\hline \multirow{9}{*}{ Body weight } & 11 & $72,356,401$ & 0.30 & 3.76 & EMX2, mRNA-hypothetical protein and KAB1271709.1 \\
\hline & 8 & $43,104,525$ & 0.30 & 3.42 & FAM184A, MCM9, ASF1 \\
\hline & 19 & $10,894,226$ & 0.34 & 3.38 & CSE1L, ARFGEF2 \\
\hline & $\mathrm{X}$ & $78,141,509$ & 0.43 & 3.30 & TSR2, WNK3 \\
\hline & $\mathrm{X}$ & $78,141,514$ & 0.43 & 3.30 & TSR2, WNK3 \\
\hline & $\mathrm{X}$ & $60,452,363$ & 0.08 & 3.16 & LPAR4, RTL3, PEG10 \\
\hline & $\mathrm{X}$ & $62,116,802$ & 0.06 & 3.12 & PBDC1, TRAPPC13 \\
\hline & 4 & $40,844,257$ & 0.16 & 3.13 & UNKNOWN \\
\hline & 18 & $29,958,631$ & 0.06 & 3.08 & DEXI, TSPYL4, CIITA \\
\hline
\end{tabular}

Table 4. Genome-wide association studies (GWAS)-identified significant single-nucleotide polymorphisms (SNPs) ( $-\log \mathrm{p}$ value $>3$ ), associated traits, and candidate genes. 


\begin{tabular}{|l|l|l|l|}
\hline SNP ID(Chr_pos) & SNP ID(Chr_pos) & SNP ID(Chr_pos) & SNP ID(Chr_pos) \\
\hline S1_63040824 & S10_13608620 & S14_31079196 & S19_10894231 \\
\hline S1_63040834 & S10_13608628 & S14_31241609 & S19_11030167 \\
\hline S1_63048213 & S10_13608631 & S14_31241643 & S19_11148798 \\
\hline S1_63445934 & S10_13608637 & S14_31244620 & S19_9631630 \\
\hline S2_14965 & S10_13608647 & S14_31359918 & S21_31508895 \\
\hline S2_99932513 & S10_13608655 & S14_31371222 & S25_262766 \\
\hline S4_40844257 & S10_13892353 & S14_31371235 & S25_262898 \\
\hline S6_14654249 & S11_70990227 & S14_31371236 & S25_263079 \\
\hline S6_24997291 & S11_71992855 & S14_31371259 & S25_263086 \\
\hline S7_75108807 & S11_72060113 & S16_34358452 & S29_10601495 \\
\hline S7_82468596 & S11_72060113 & S16_34483240 & S31_16977384 \\
\hline S7_82483675 & S11_72350029 & S17_75949 & S31_16998649 \\
\hline S7_82483685 & S11_72356390 & S18_29830420 & S33_4467956 \\
\hline S8_43104525 & S11_72356400 & S18_29958631 & S34_6774561 \\
\hline S8_59919313 & S11_72356401 & S18_29963432 & S34_6774561 \\
\hline S8_72594548 & S11_72356436 & S18_29963702 & S35_6600815 \\
\hline S8_72594549 & S11_74288613 & S18_29985605 & S35_9257022 \\
\hline S8_72594593 & S11_74292760 & S18_30061144 & S35_9290500 \\
\hline S8_72594633 & S11_81210420 & S18_30075711 & SX_113249264 \\
\hline S8_72594639 & S12_5711 & S18_30105059 & SX_60452363 \\
\hline S9_15226704 & S13_50711877 & S19_10237641 & SX_62116802 \\
\hline S9_22550930 & S14_30854110 & S19_10237661 & SX_6887230 \\
\hline S9_22738164 & S14_30865065 & S19_10328831 & SX_78141509 \\
\hline S9_53275637 & S14_30865085 & S19_10433012 & SX_78141514 \\
\hline S9_53275650 & S14_30865111 & S19_10894226 & \\
\hline
\end{tabular}

Table 5. List of SNP markers associated with camel growth at $-\log p$ value $\geq 2.5$.

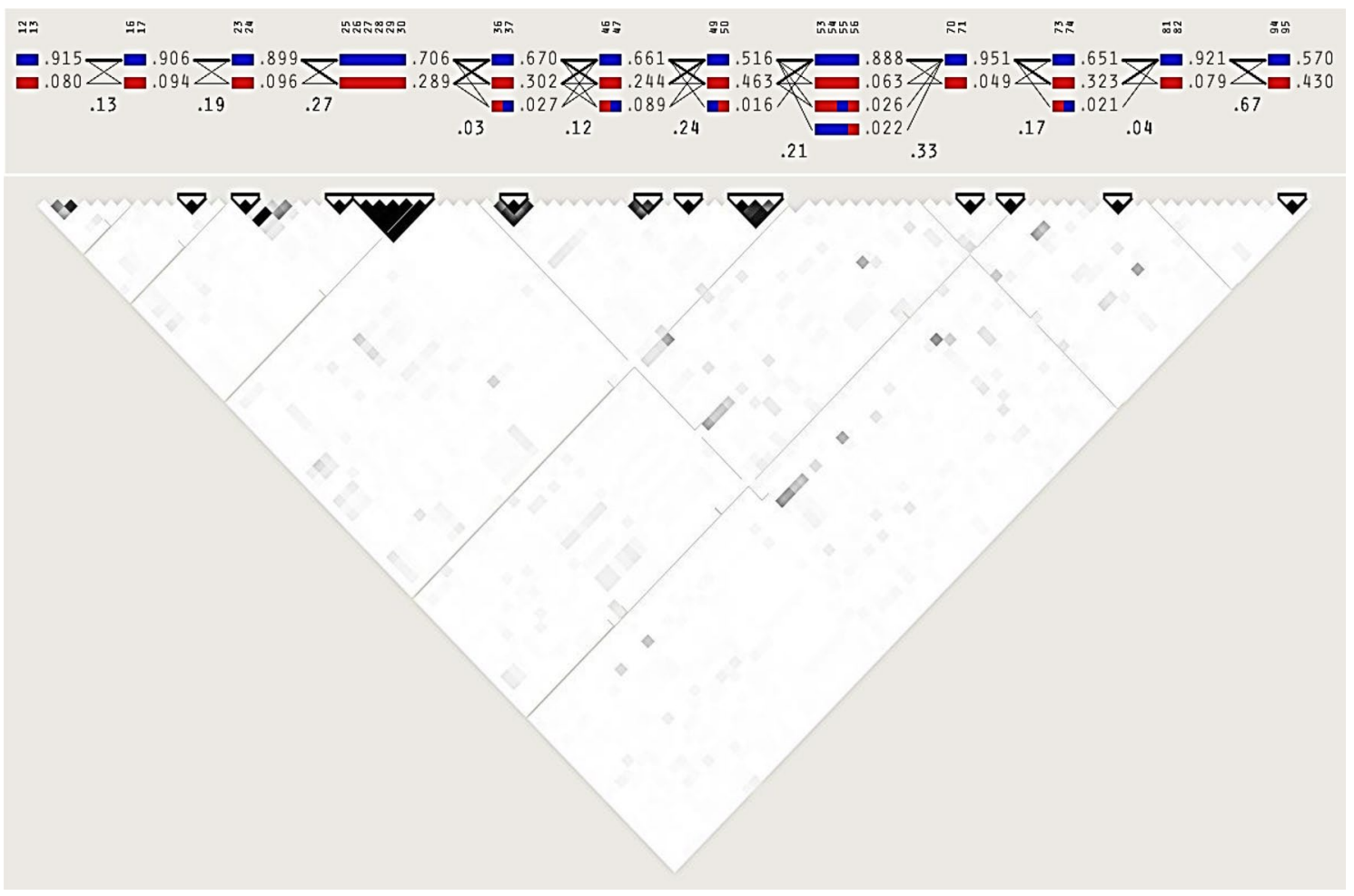

Figure 7. the Haplotype Blocks of the 99 associated SNPs with birth weight, daily gain, and body weight. 


\begin{tabular}{|c|c|c|c|c|c|c|}
\hline Trait & Haplotype & NSNP* & NSIG & ISIG & EMP1 & SNPS \\
\hline \multirow{12}{*}{ Birth Weight } & Haplotype1 & 2 & 0 & 0 & 1 & $\mathrm{NaN}^{* *}$ \\
\hline & Haplotype2 & 2 & 2 & 1 & $1.00 \mathrm{E}-04$ & S8_72594549 \\
\hline & Haplotype3 & 2 & 2 & 1 & 0.0121 & S9_53275650 \\
\hline & Haplotype4 & 6 & 4 & 1 & 0.0413 & S10_13608620 \\
\hline & Haplotype5 & 2 & 2 & 1 & 0.0243 & S11_72356401 \\
\hline & Haplotype6 & 2 & 0 & 0 & 1 & $\mathrm{NaN}$ \\
\hline & Haplotype7 & 2 & 0 & 0 & 1 & $\mathrm{NaN}$ \\
\hline & Haplotype8 & 4 & 0 & 0 & 1 & $\mathrm{NaN}$ \\
\hline & Haplotype9 & 2 & 2 & 1 & $4.00 \mathrm{E}-04$ & S19_10237661 \\
\hline & Haplotype10 & 2 & 0 & 0 & 1 & $\mathrm{NaN}$ \\
\hline & Haplotype11 & 2 & 0 & 0 & 1 & $\mathrm{NaN}$ \\
\hline & Haplotype12 & 2 & 2 & 1 & 0.009299 & SX_78141514 \\
\hline \multirow{12}{*}{ Gain/day } & Haplotype1 & 2 & 0 & 0 & 1 & $\mathrm{NaN}$ \\
\hline & Haplotype2 & 2 & 0 & 0 & 1 & $\mathrm{NaN}$ \\
\hline & Haplotype3 & 2 & 0 & 0 & 1 & $\mathrm{NaN}$ \\
\hline & Haplotype4 & 6 & 0 & 0 & 1 & $\mathrm{NaN}$ \\
\hline & Haplotype5 & 2 & 0 & 0 & 1 & $\mathrm{NaN}$ \\
\hline & Haplotype6 & 2 & 2 & 1 & $2.00 \mathrm{E}-04$ & S14_30865085 \\
\hline & Haplotype7 & 2 & 1 & 1 & 0.0391 & S14_31241643 \\
\hline & Haplotype8 & 4 & 1 & 1 & 0.05859 & S14_31371259 \\
\hline & Haplotype9 & 2 & 0 & 0 & 1 & $\mathrm{NaN}$ \\
\hline & Haplotype10 & 2 & 0 & 0 & 1 & $\mathrm{NaN}$ \\
\hline & Haplotype11 & 2 & 0 & 0 & 1 & $\mathrm{NaN}$ \\
\hline & Haplotype12 & 2 & 2 & 1 & 0.0011 & SX_78141514 \\
\hline \multirow{12}{*}{ Body weight } & Haplotype1 & 2 & 0 & 0 & 1 & $\mathrm{NaN}$ \\
\hline & Haplotype2 & 2 & 2 & 1 & $1.00 \mathrm{E}-04$ & S8_72594549 \\
\hline & Haplotype3 & 2 & 2 & 1 & 0.0128 & S9_53275637 \\
\hline & Haplotype4 & 6 & 0 & 0 & 1 & $\mathrm{NaN}$ \\
\hline & Haplotype5 & 2 & 2 & 1 & 0.007299 & S11_72356401 \\
\hline & Haplotype6 & 2 & 2 & 1 & 0.006499 & S14_30865111 \\
\hline & Haplotype7 & 2 & 2 & 1 & 0.0203 & S14_31241643 \\
\hline & Haplotype8 & 4 & 4 & 1 & 0.0395 & S14_31371259 \\
\hline & Haplotype9 & 2 & 2 & 1 & 0.0034 & S19_10237661 \\
\hline & Haplotype10 & 2 & 0 & 0 & 1 & $\mathrm{NaN}$ \\
\hline & Haplotype11 & 2 & 2 & 1 & 0.005999 & S25_263086 \\
\hline & Haplotype12 & 2 & 2 & 1 & 0.038 & SX_78141514 \\
\hline
\end{tabular}

Table 6. the haplotype-traits association analysis. ${ }^{\star}$ NSNP: Number of SNPs in Haplotype, NSIG: Total number of SNPs below p-value threshold $(\mathrm{p}<0.05)$ ), ISIG: Number of significant SNPs also passing LD-criterion (R-squared >0.50), EMP1: Empirical set-based p-value, SNPS: List of SNPs in the Haplotype. ** Not a Number.

\begin{tabular}{|l|l|l|l|l|}
\hline \multirow{2}{*}{ Trait } & All 14,522 SNPs & \multicolumn{2}{l|}{ 99 Associated SNPs } \\
\cline { 2 - 5 } & r & b & r & b \\
\hline Birth weight & $0.96 \pm 0.0004$ & $0.39 \pm 0.011$ & $0.85 \pm 0.0003$ & $0.55 \pm 0.0007$ \\
\hline Daily gain & $0.66 \pm 0.002$ & $0.20 \pm 0.009$ & $0.56 \pm 0.0008$ & $0.28 \pm 0.0005$ \\
\hline Body weight & $0.86 \pm 0.0009$ & $0.23 \pm 0.009$ & $0.64 \pm 0.0009$ & $0.19 \pm 0.0004$ \\
\hline
\end{tabular}

Table 7. The averaged correlation ( $\mathrm{r}$ ) and regression coefficient $(\mathrm{b})$ between the observed values and the GEBVs predicted from two SNPs sets: (1) all 14,522 SNPs and (2) the 99 associated SNPs using BGLR package (BRR model). 


\begin{tabular}{|l|l|l|l|l|l|}
\hline & Model & $\mathbf{r}$ & SD & RMSE & $\mathbf{R}^{\mathbf{2}}$ \\
\hline \multirow{5}{*}{ Birth weight } & BRR & 0.62 & 0.109 & 7.78 & 0.37 \\
\cline { 2 - 6 } & Bayes A & 0.61 & 0.103 & 7.876637 & 0.35 \\
\cline { 2 - 6 } & Bayes B & 0.62 & 0.101 & 7.826124 & 0.36 \\
\hline & Bayes C & 0.62 & 0.109 & 7.826 & 0.36 \\
\hline \multirow{5}{*}{ Baily gain } & BRR & 0.82 & 0.069 & 69.064 & 0.67 \\
\cline { 2 - 6 } & Bayes A & 0.70 & 0.061 & 87.20 & 0.47 \\
\cline { 2 - 6 } & Bayes B & 0.69 & 0.067 & 88.12 & 0.46 \\
\cline { 2 - 6 } & Bayes C & 0.70 & 0.068 & 87.036 & 0.47 \\
\hline \multirow{5}{*}{} & BRR & 0.57 & 0.094 & 37.66672 & 0.29 \\
\cline { 2 - 6 } & Bayes A & 0.48 & 0.096 & 40.3208 & 0.20 \\
\cline { 2 - 6 } & Bayes B & 0.48 & 0.099 & 40.31 & 0.20 \\
\cline { 2 - 6 } & Bayes C & 0.48 & 0.100 & 40.41 & 0.20 \\
\hline
\end{tabular}

Table 8. The GEBVs accuracy predicted from the 99 SNPs using BGLR package.

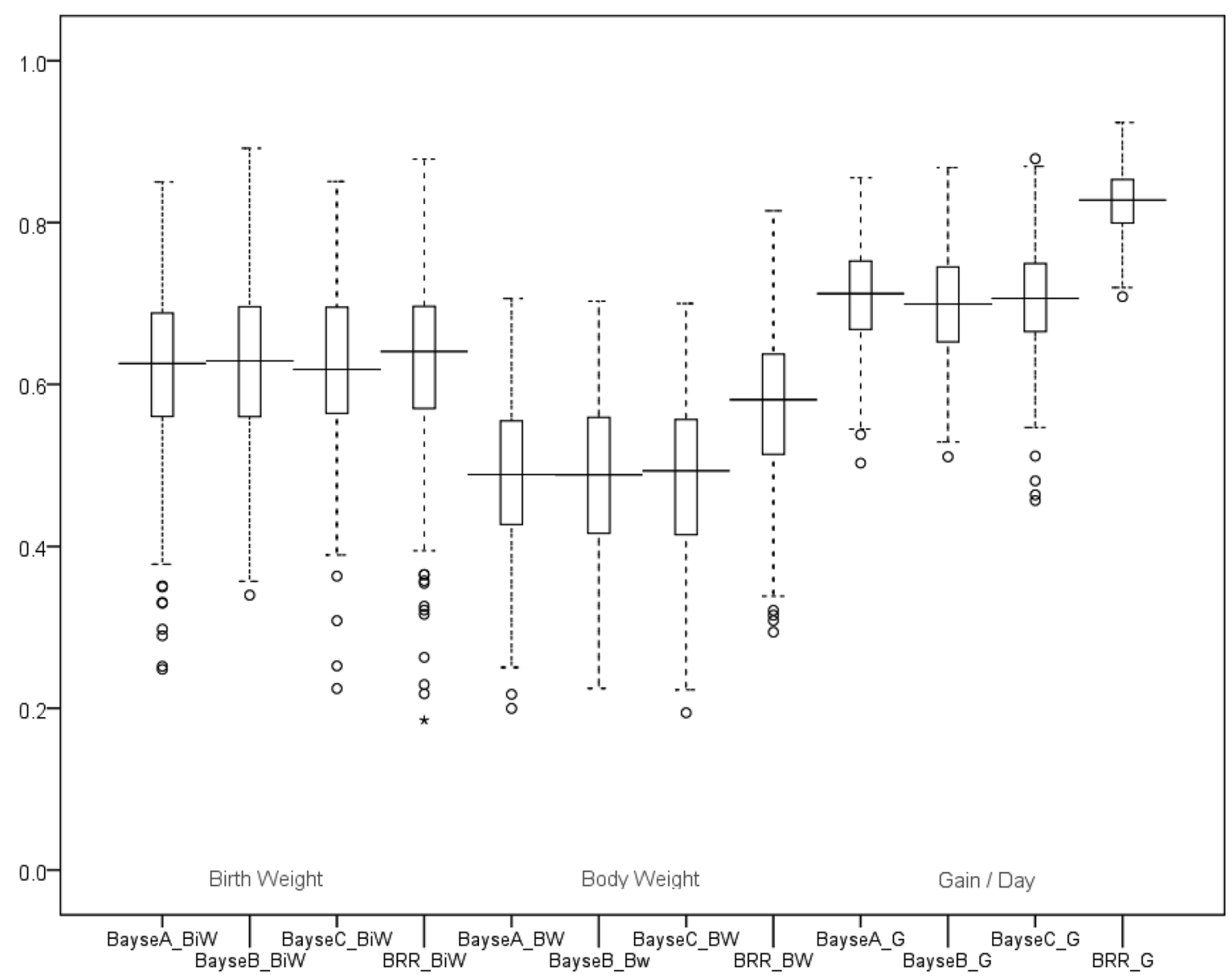

Figure 8. The accuracy of predicted GEBVs from the 99 SNPs using BGLR package.

Received: 15 November 2020; Accepted: 26 March 2021

Published online: 07 April 2021

\section{References}

1. Hashim, W. M. et al. Dromedary camels in Sudan, types and sub types, distribution and movement. Int. J. Pharm. Res. Anal. 5, 8-12 (2015).

2. Bernabucci, U., Ronchi, B., Lacetera, N. \& Nardone, A. Markers of Oxidative Status in Plasma and Erythrocytes of Transition Dairy Cows During Hot Season. J. Dairy Sci. 85, 2173-2179 (2002).

3. Abri, M. A. A. \& Faye, B. Genetic improvement in dromedary camels: challenges and opportunities. Front. Genet. 10, 167-171 (2019).

4. Bitaraf Sani, M. et al. Genome-Wide Diversity, Population Structure and Demographic History of Dromedaries in the Central Desert of Iran. Genes 11, 599. https://doi.org/10.3390/genes11060599 (2020). 
5. Scienski, K. et al. Genetic variability in a Holstein population using SNP markers and their use for monitoring mating strategies. Revista Mexicana de Ciencias Pecuarias. 10, 643-663 (2019).

6. Li, Y. \& Kim, J. J. Effective Population Size and Signatures of Selection Using Bovine 50K SNP Chips in Korean Native Cattle (Hanwoo). Evol. Bioinform. 11, 143-153 (2015).

7. Parker, C. C. et al. Genome-wide association study of behavioral, physiological and gene expression traits in outbred CFW mice. Nat. Genet. 48, 919. https://doi.org/10.1038/ng.3609 (2016).

8. Kang, Y. et al. Genome-wide association of drought-related and biomass traits with HapMap SNPs in Medicago truncatula. Plant Cell Environ. 38, 1997-2011 (2015).

9. He, J. et al. Genotyping-by-sequencing (GBS) an ultimate marker-assisted selection (MAS) tool to accelerate plant breeding. Front. Plant Sci. 5, 484 (2014).

10. Bahbahani, H. M. et al. Genome diversity and signatures of selection for production and performance traits in dromedary camels. Front. Genet. 10, 893 (2019).

11. Lu, Z. et al. Genome-wide association study of body weight traits in chinese fine-wool sheep. Animals 10, 170. https://doi.org/10. 3390/ani10010170 (2020).

12. Hirschhorn, J. N. \& Daly, M. J. Genome-wide association studies for common diseases and complex traits. Nat. Rev. Genet. 6, 95-108 (2005).

13. Li, B. et al. High-density genome-wide association study for residual feed intake in Holstein dairy cattle. J. Dairy Sci. 102, 1106711080 (2019).

14. Liu, Z. et al. Genome-wide association analysis of egg production performance in chickens across the whole laying period. BMC Genet. 20, 67. https://doi.org/10.1186/s12863-019-0771-7 (2019).

15. Ghasemi, M., Zamani, P., Vatankhah, M. \& Abdoli, R. Genome-wide association study of birth weight in sheep. Animals 13, 1797-1803 (2019).

16. Tang, Z. et al. Genome-wide association study reveals candidate genes for growth relevant traits in pigs. Frontiers in Genet. 10, 302. https://doi.org/10.3389/fgene.2019.00302 (2019).

17. Wei, C. H. \& Liu, C. S. Encyclopedia of Modern Sheep Production Technology 70-77 (China Agriculture Press, Beijing, 2014).

18. Salehi, M. \& Gharahdaghi A. A. Camel Production Potential and Recent Research in Iran. Preprint at: http://agris.fao.org/agrissearch (2013).

19. Khodai, S. A. The report on camel production systems and the socio-economics of camel herders in the Islamic Republic of Iran. Cardn/Acsad/Camel/P107/2002. Deputy for Livestock Affairs Directorate of Animal Breeding. Iran, 4-10 (2004).

20. IBM Corp. Released 2013. IBM SPSS Statistics for Windows, Version 22.0. Armonk, NY: IBM Corp.

21. Javanrouh, A. et al. Optimization on salting out method for DNA extraction from animal and poultry blood cells. In Proceedings of the 57th Ann Meet European Assoc Anim Prod, Antalya, Turkey, 17-20 September (2006).

22. Li, H. \& Durbin, R. Fast and accurate long-read alignment with Burrows-Wheeler transform. Bioinformatics 26, 589-595 (2010).

23. McKenna, A. et al. The Genome Analysis Toolkit: a MapReduce framework for analyzing next-generation DNA sequencing data. Genome Res. 20, 1297-1303 (2010).

24. Pembleton, L. W., Cogan, O. I. N. \& Forster, J. W. StAMPP: An R package for calculation of genetic differentiation and structure of mixed-ploidy level populations. Mol. Ecol. Resour. 13, 946-952 (2013).

25. Knaus, B. J. \& Grünwald, N. J. vcfr: a package to manipulate and visualize variant call format data in R. Mol. Ecol. Resour. 17, 44-53 (2017).

26. Kamvar, Z. N., Tabima, J. F. \& Grünwald, N. J. Poppr: an R package for genetic analysis of populations with clonal, partially clonal, and/or sexual reproduction. PeerJ 2, e281 (2014).

27. Neuwirth, E. \& Brewer, R. C. ColorBrewer palettes. R package version,.1-1.2 https://CRAN.R-project.org/package=RColorBrew er (2014).

28. Bradbury, P. J. TASSEL: Software for association mapping of complex traits in diverse samples. Bioinformatics 23, 2633-2635 (2007).

29. Barrett, J. C., Fry, B., Maller, J. \& Daly, M. J. Haploview: analysis and visualization of LD and haplotype maps. Bioinformatics 21, 263-265 (2004).

30. Li, M., Yeung, J. M., Cherny, S. S. \& Sham, P. C. Evaluating the effective numbers of independent tests and significant p-value thresholds in commercial genotyping arrays and public imputation reference datasets. Hum. Genet. 131, 747-756 (2012).

31. Pérez, P. et al. Genome-wide regression and prediction with the BGLR statistical package. Genetics 198, 483-495 (2014).

32. Zhang, Z. et al. Best linear unbiased prediction of genomic breeding values using a trait-specific marker-derived relationship matrix. PLOS ONE 5, e12648. https://doi.org/10.1371/journal.pone.0012648 (2010).

33. Resende, M. D. et al. Genomic selection for growth and wood quality in Eucalyptus: capturing the missing heritability and accelerating breeding for complex traits in forest trees. New Phytol. 194, 116-128 (2012).

34. Shikha, M. et al. Genomic selection for drought tolerance using genomewide SNPs in maize. Front. Plant Sci. 8, 550. https://doi. org/10.3389/fpls.2017.00550 (2017).

35. genome association and prediction integrated tool. Lipka, A. E. et al. (2012). GAPIT. Bioinformatics 28, 2397-2399 (2012).

36. Tang, Y. et al. GAPIT version 2: an enhanced integrated tool for genomic association and prediction. Plant Genome. 9, 9. https:// doi.org/10.3835/plantgenome2015.11.0120 (2016).

37. Yano, K., Yamamoto, E. \& Aya, K. Genome-wide association study using whole-genome sequencing rapidly identifies new genes influencing agronomic traits in rice. Nat. Genet. 48, 927-934 (2016).

38. De Tayrac, M. et al. Genome-wide association study identifies TF as a significant modifier gene of iron metabolism in HFE hemochromatosis. J. Hepatol. 62, 664-672 (2015).

39. Martínez, R. et al. Genome-wide association study for birth, weaning and yearling weight in Colombian Brahman cattle. Genet. Mol. Biol. 40, 453-459 (2017).

40. Wang, Y. et al. Genetic architecture of quantitative traits in beef cattle revealed by genome wide association studies of imputed whole genome sequence variants: II: carcass merit traits. BMC Genomics 21, 38. https://doi.org/10.1186/s12864-019-6273-1p.36 (2020).

41. An, B. et al. Multiple association analysis of loci and candidate genes that regulate body size at three growth stages in Simmental beef cattle. BMC Genet. 21, 32. https://doi.org/10.1186/s12863-020-0837-6 (2020).

42. Edea, Z. et al. Genome-wide association study of carcass weight in commercial Hanwoo cattle. Asian Australas. J. Anim. Sci. 31, 327-334 (2018).

43. Jarquin, D., Specht, J. \& Lorenz, A. Prospects of genomic prediction in the USDA Soybean Germplasm Collection: Historical data creates robust models for enhancing selection of accessions. G3: Genes Genomes Genet. 6, 2329-2341 (2016).

44. Zhang, J., Song, Q., Cregan, P. B. \& Jiang, G. L. Genome-wide association study, genomic prediction and marker-assisted selection for seed weight in soybean (Glycinemax). Theor. Appl. Genet. 129, 117-130 (2016).

45. Duhnen, A. et al. Genomic selection for yield and seed protein content in soybean: a study of breeding program data and assessment of prediction accuracy. Crop Sci. 57, 1325-1337 (2017).

46. Piccoli, M. L. et al. Genomic predictions for economically important traits in Brazilian Braford and Hereford beef cattle using true and imputed genotypes. BMC Genet. 18, 2. https://doi.org/10.1186/s12863-017-0475-9 (2017).

47. Zhu, B. et al. Accuracies of genomic prediction for twenty economically important traits in Chinese Simmental beef cattle. Anim. Genet. 50, 634-643 (2019). 
48. Brito, L. F. et al. Prediction of genomic breeding values for growth, carcass and meat quality traits in a multi-breed sheep population using a HD SNP chip. BMC Genet. 18, 7. https://doi.org/10.1186/s12863-017-0476-8 (2017).

49. Ibáñez-Escriche, N., Forni, S., Noguera, J. L. \& Varona, L. Genomic information in pig breeding: science meets industry needs. Livest. Sci. 166, 94-100 (2014).

50. Ge, F. et al. Accuracies of genomic prediction for growth traits at weaning and yearling ages in yak. Animals 10, 1793. https://doi. org/10.3390/ani10101793 (2020).

51. Habier, D., Fernando, R. L. \& Dekkers, J. C. Genomic selection using low-density marker panels. Genetics 182, 343-353 (2009).

52. Garrick, D. J. The nature, scope and impact of genomic prediction in beef cattle in the United States. Genet. Sel. Evol. 43, 17. https:// doi.org/10.1186/1297-9686-43-17 (2011).

53. Garrick, D. J., Taylor, J. F. \& Fernando, R. L. Deregressing estimated breeding values and weighting information for genomic regression analyses. Genet Sel Evol 41, 55. https://doi.org/10.1186/1297-9686-41-55 (2009).

54. Hayes, B. J. et al. Accuracy of marker-assisted selection with single markers and marker haplotypes in cattle. Genet Res (Camb). 89, 215-220 (2007).

55. Georges, M., Charlier, C. \& Hayes, B. Harnessing genomic information for livestock improvement. Nat. Rev. Genet. 20, 135-156 (2019).

\section{Acknowledgements}

We would like to thank the camel farmers in Yazd province for providing samples. PB acknowledges funding from the Austrian Science Fund (FWF): P29623-B25. This research was jointly funded by Animal Science Research Institute of Iran (ASRI), Animal Breeding Center of Iran, and Yazd Agricultural and Natural Resources Research and Education Center, grant number 34-64-1357-005-970180.

\section{Author contributions}

Conceptualization, M.B.S.; J.Z.H.; S.E.; M.H.B.; A.B.; M. Z and N.S.; methodology, M.B.S.; J.Z.H.; M.H.B.; M.A.F.; M.S.; A.T.S.; A.T.; and A.Sh.N.; software, M.B.S.; and M.A.F.; formal analysis, M.B.S; investigation, M.B.S.; and J.Z.H.; writing_original draft preparation, M.B.S.; writing—review and editing, S.E; M.H.B.; P.B.; V.L and M.A.F.; visualization, M.B.S; supervision, M.H.B.; S.E.; M.A.F.; and P.B. All authors reviewed the manuscript.

\section{Competing interests}

The authors declare no competing interests.

\section{Additional information}

Correspondence and requests for materials should be addressed to M.B.S.

Reprints and permissions information is available at www.nature.com/reprints.

Publisher's note Springer Nature remains neutral with regard to jurisdictional claims in published maps and institutional affiliations.

(c) (i) Open Access This article is licensed under a Creative Commons Attribution 4.0 International License, which permits use, sharing, adaptation, distribution and reproduction in any medium or format, as long as you give appropriate credit to the original author(s) and the source, provide a link to the Creative Commons licence, and indicate if changes were made. The images or other third party material in this article are included in the article's Creative Commons licence, unless indicated otherwise in a credit line to the material. If material is not included in the article's Creative Commons licence and your intended use is not permitted by statutory regulation or exceeds the permitted use, you will need to obtain permission directly from the copyright holder. To view a copy of this licence, visit http://creativecommons.org/licenses/by/4.0/.

(C) The Author(s) 2021 